\title{
Study on the design strategy of prefabricated steel structure green farm house in cold areas_taking a farm house design practice in shandong, china as an example
}

\author{
Ninghan Sun ${ }^{1, *}$, Yanqiu Cui ${ }^{1}$ \\ ${ }^{1}$ College of Architecture and Urban Planning, Shandong Jianzhu University, Jinan; 250100, China
}

\begin{abstract}
With the vigorous promotion of the development and construction of "beautiful countryside" in China, the irrationality of the functional space of rural farmhouses and the energy conservation and consumption reduction of farmhouses have become urgent problems. In this paper, the design practice of a green agricultural house with prefabricated steel structure in Shandong province was taken as an example. Based on a variety of factors such as environmental characteristics, regional characteristics, and technical conditions, design and application research were conducted from the aspects of building shape and functional space design, appropriate green building technology. What's more, the energy consumption simulation software was used for its quantitative analysis of energy saving effects and indoor temperature, and a green farm house design strategy adapted to the characteristics of cold climate, regional characteristics, and future development trends was discussed, which was intended to provide a technical reference for the construction of beautiful countryside.
\end{abstract}

\section{Introduction}

In recent years, the country has established " Construct beautiful countryside" as a goal for future development. At present, China has a rural farmhouse area of about 22.1 billion square meter. Traditional design concepts and construction methods often make rural farmhouses have high energy consumption, low comfort and poor environment[1-3]. This paper discusses the design principles of prefabricated steel structure green farm house in Shandong area and carries out specific design practices based on this, which provides a certain theoretical and technical reference for achieving energy saving, emission reduction and green sustainability of farm house.

\section{Design Principles of Green Farm Houses in Shandong}

\subsection{Environmental adaptability}

Green farmhouses first need to adapt to the local climate and geographical environment. Shandong is located in a cold region and belongs to a temperate monsoon climate. It is hot and rainy with southeast winds prevailing in summer, and cold with little rain, snow and northwest wind prevailing in winter. Therefore, the building needs to consider both summer insulation and winter insulation. When designing the plan, we should take into account the characteristics of the climate and geographical environment, and give full consideration to the layout and shape of the building, the division of the planar space, and the envelope structure, and finally create a comfortable indoor physical environment to meet the needs of inhabitants.

\subsection{Technical adaptability}

When designing and constructing green farmhouses, we must pay attention to the use of new building technologies. The principle of technology selection is that it should be suitable for the development level of the farm house itself. In addition, it should also follow the concept of taking local materials according to local conditions, and fully retain the tradition and regional characteristics of the farm house. Specifically, firstly, an energy-saving and environmentally-friendly structural system should be selected; secondly, we should pay attention to the design of the envelope structure to make it suitable for the structural system of the building and satisfy the needs of the indoor physical environment[4]; finally, appropriate technologies must be used to strengthen the use of renewable energy sources.

\subsection{Economic feasibility}

Economic issues are one of the main concerns of residents when building farm houses. Generally speaking, most rural farm houses are self-funded and self-built, so the economic affordability of residents should be fully considered. The total capital investment of the farm

\footnotetext{
* Corresponding author: 125363485@qq.com
} 
house is the capital investment in the whole life cycle. In order to reduce this cost, methods and measures should be taken from the two aspects of construction cost and operating cost.

\section{Design Application Research}

Based on the above design principles, and combined with the design practice of a farm house in Zibo City, Shandong Province, the design method of prefabricated steel structure green farm house in rural areas is discussed, and the farm house is designed to achieve practical, comfortable and energy-saving design goals.

\subsection{Architectural shape and functional space design strategy based on environmental analysis}

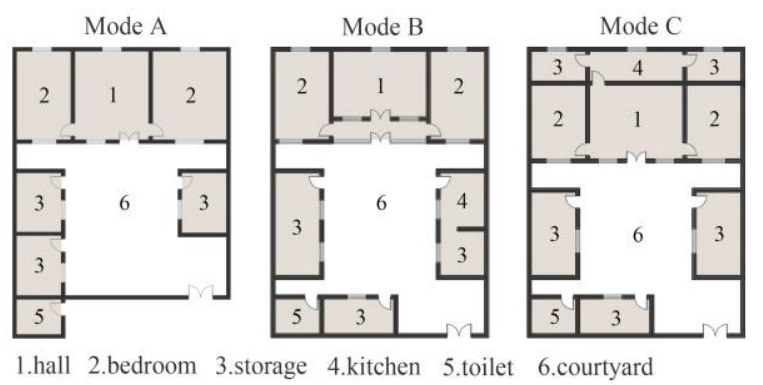

Figure 1 Typical layout mode of traditional farmhouses

According to the local environmental factors, the current typical farmhouse layout in the village where the project is located is investigated and analyzed. There are mainly three layout modes in this area, such as Mode A, B, and $C$ (Figure 1). In model $A$, the north room is the main living space, and the hall is also used as the kitchen and dining room, and the bedroom is also used as the guest space. The toilets need to use the public toilets outside the farmhouse. There are some problems in functional space, inconvenience, and flow lines. The stove in the hall is used in winter, which can provide a certain amount of heat to the room, but in summer it will cause the indoor temperature to be too high, and it is difficult to adapt to the local climatic conditions in terms of indoor thermal environment. In Mode B, the kitchen is moved from the house to the private room. The courtyard is equipped with aqua privies for its own use. The functional space has begun to focus on independence and integrity, but there are still some inconveniences in use. There is a heating corridor on the south side of the house. Living space cannot use the heat generated by the kitchen in winter, so it is difficult to maintain a comfortable level in terms of indoor thermal environment. In Mode C, the kitchen and storage space are located on the north side of the hall, which is convenient for daily use. The layout of the functional space is more reasonable than the two previous modes; the auxiliary space on the north side is beneficial to the insulation of the hall and the bedroom. The heat generated by the kitchen is also returned in winter to improve the comfort, and the indoor thermal environment is better than the former two. In terms of building shape, the three models have common characteristics, that is, each house is scattered around the courtyard. The building shape is a single-layer rectangular block with a wide surface and a small depth. It has a large shape coefficient and is not conducive to building energy conservation. Through the analysis of the above three layout modes, we can see that traditional farmhouses need to be improved in terms of functional zoning, indoor thermal environment, and body shape design. Now combining the design practices of green farmhouses in Shandong, we will further explore the buildings suitable for local environmental factors, shape and function space design strategies.

\subsubsection{Architectural layout design}

In response to the cold winter conditions in Zibo, Shandong, the green farmhouse adopts a compact collective layout, integrating the various functional rooms scattered in the courtyard in the traditional layout mode into one block. This block has two layers and the depth of the space is moderately increased, which form is approximately a square shape, unnecessary bump changes on the shape are avoided, and the shape factor is minimized as much as possible[5]. The roof form is a sloping roof, which continues the traditional rural style while adapting to the cold winter weather conditions (Figure 2).

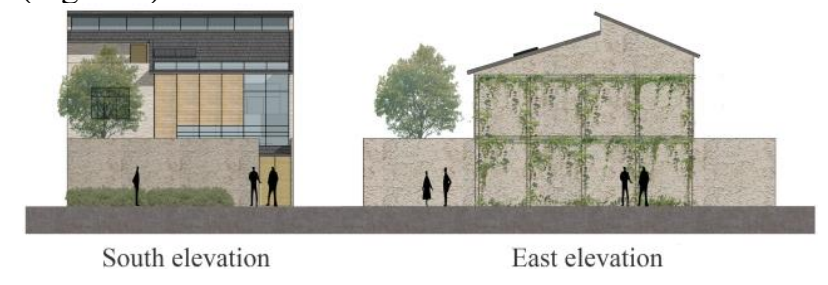

Figure 2 Elevation of green farmhouse

\subsubsection{Functional space layout design}

In this scheme, the functional public spaces such as the living room, dining room, and kitchen are arranged on the first floor. Residents can perform activities such as meeting guests, family gatherings, and dining. Functional spaces with strong privacy, such as bedrooms, are arranged on the second floor to ensure the privacy of residents; an outdoor platform can be used for drying; an independent front yard and back yard are set up outdoors, and the front yard is used for daily communication activities. The backyard is used for agricultural tool storage and livestock breeding. The functional spaces are independent of each other and do not affect each other, avoiding the problem of mixed functions and streamline crossing in the traditional layout. In addition, the design of the auxiliary space in the scheme design has been greatly improved compared with the traditional farmhouse. First, the toilet is no longer outside, it is set indoors and modern sanitary ware is applied. Second, affected by factors such as climate characteristics, cultural customs, etc., in addition to the use of gas stoves and other modern equipment in the kitchen space, which 
has special features in terms of function and spatial layout, there is also a traditional floor stove as a continuation of the residents' traditional lifestyle and local memory. In terms of the division of thermal zones, the auxiliary spaces such as garages, bathrooms, and kitchens are arranged in the north direction to block the infiltration of cold wind from the north in winter. The living room, bedroom, elderly bedroom and other rooms with high indoor physical environment requirements are arranged in the south, which can make better use of sunshine (Figure 3).
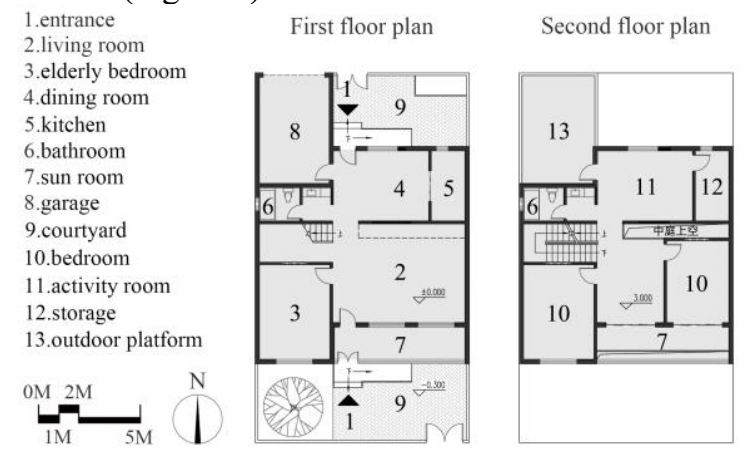

Figure 3 Plan of green farmhouse
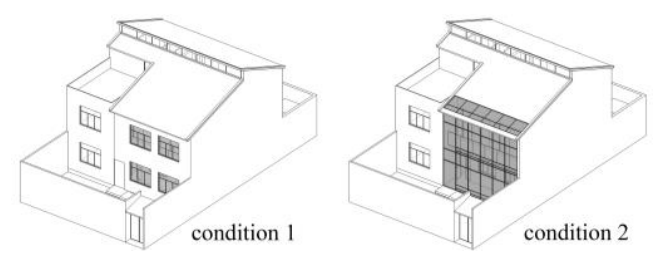

Figure 4 Two conditions with and without sunspace

Setting up a sunspace is a common method to promote energy saving in rural areas in cold areas[6]. The computer software Design Builder is now used to simulate the difference in energy consumption of farm houses under two operating conditions with and without sunspace. In condition 1, in accordance with the national design standards stipulating, the window-to-wall ratio south facade of the farm house is set to simulate the state without sunspace[7]; in condition 2, some south facades and roofs are set to be glass surfaces to simulate the state with sunspace, and all other conditions remain the same (Figure 4). Based on simulation calculations, the annual heating energy consumption per unit area of condition 2 is $8.89 \mathrm{~kW} \cdot \mathrm{h} / \mathrm{m}^{2}$ lower than that of condition 1 . Therefore, the green farmhouse is set as the condition 2 with sunspace. This sunspace is adjacent to the living room and bedroom. The partition wall is made of local masonry with strong heat storage capacity, and the outside of the thermal storage wall is equipped with thermal insulation curtains to prevent large temperature fluctuations in the sunlight at night in winter from affecting the internal room.

The functional space layout of green farmhouses is also affected by natural ventilation. Based on the simulation of CFD software, the positions and sizes of functional spaces and doors and windows in the farmhouse scheme have been optimized, so that green farmhouses can use natural ventilation more effectively. The optimized farmhouse has $1.8 \mathrm{~m} * 1.5 \mathrm{~m}$ large windows in the south direction and $1.2 \mathrm{~m} * 1.5 \mathrm{~m}$ small windows in the north. The main function rooms are located on the north-south wind tunnel, which can form a smooth wind through the hall. At the same time, a south-facing skylight was opened at the junction of the two slopes on the roof of the sloping house. Under the skylight is an indoor high atrium. The rooms on both sides of the atrium are equipped with high windows for ventilation, so these rooms can be heat-pressurized (Figure 5).

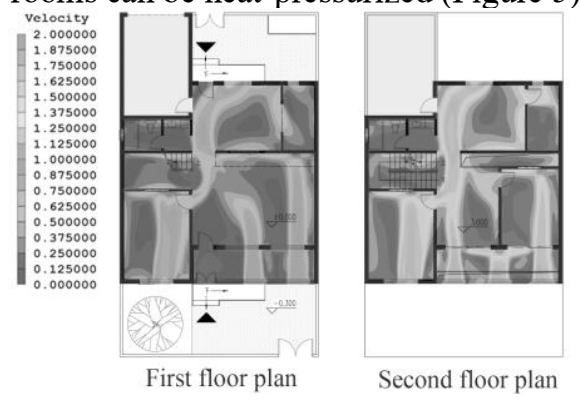

Figure 5 Indoor wind speed chart

In addition, as the aging problem in rural areas becomes more and more obvious, the functional space of green farmhouses should pay more attention to the design for the elderly. The elderly room is located on the first floor to reduce unnecessary climbing and climbing behavior of the elderly. The area guarantees that the wheelchair can pass freely in the room, and special handrails are provided in the elderly room and the toilet on the first floor for daily use by the elderly. The elderly room is close to the sunshine room, and the elderly can move here when there is sufficient sunlight. There is an accessible ramp at the entrance of the farmhouse, which is convenient for wheelchairs.

\subsection{Analysis of green technology design of rural house based on regional characteristics}

The building technology used in the design of the farm house should be suitable for itself, and try to avoid the application of unsuitable technologies with complicated practices and high costs. At the same time, it fully combines the local characteristics of the local area and pays attention to the application of local materials and regional traditional practices.

\subsubsection{Architectural structural system design}

The structural systems of traditional farmhouses in Shandong are mostly brick-concrete structures. In recent years, some new farmhouses have adopted reinforced concrete frame structures. Both of these structures are not conducive to environmental protection and sustainable development. Therefore, this green farm house plan chose prefabricated steel structure system. The system has a high degree of assembly, convenient construction and small amount of work; the system is more environmentally friendly, steel can be recycled, and it has lower carbon emissions during production and construction; the system also has very good flexibility as the strong bearing capacity of steel members forming 
large spaces, so the room organization of farmhouses is more flexible. For example, if residents need to accompany the elderly in the future, family rooms can be set up on the first floor. If residents need more bedroom space in the future, the second-floor activity room will be changed to the second bedroom. When the resident needs to take care of the baby in the future, the second-floor bedroom can be expanded into a family room, etc. (Figure 6).
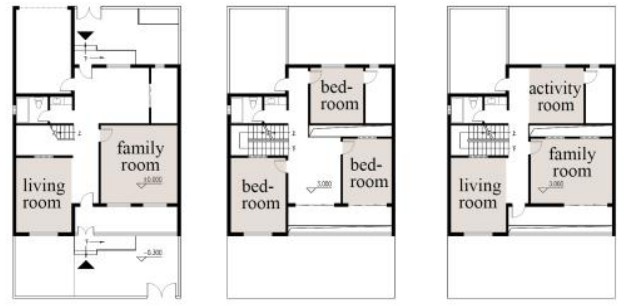

Figure 6 Function change of farm house

\subsubsection{Design of the envelope structure}

The performance of the envelope structure of the farm house has an important impact on the energy consumption of the building. In terms of external walls, in order to further improve the insulation effect, the green farm house adopts double-layer autoclaved light aeration inside and outside. The practice of concrete wall panels and EPS panels in the middle is also more suitable for prefabricated steel structure systems. After calculation, the total heat transfer coefficient of the wall is $0.24 \mathrm{~W} / \mathrm{m}^{2} \cdot \mathrm{K}$, which is less than the exterior wall specified limit of $0.65 \mathrm{~W} / \mathrm{m}^{2} \cdot \mathrm{K}$ of rural houses[7]. As for the roof, the roofing materials are common local tiles. The structural panels are autoclaved lightweight aerated concrete slabs. In order to enhance the thermal insulation performance, a layer of $100 \mathrm{~mm}$ thick compressed straw boards was added above the indoor suspended ceiling. After calculation, the total heat transfer coefficient is $0.28 \mathrm{~W} / \mathrm{m}^{2} \cdot \mathrm{K}$, which is less than the limit of $0.50 \mathrm{~W} / \mathrm{m}^{2} \cdot \mathrm{K}$ specified on the roof of a farm house in cold areas[7]. The summer in Shandong is hot, so the surrounding structure must be provided with sunshade facilities. The sunrooms and windows on the south side of the farmhouse should use lower-cost, more flexible rolling shades. Based on the principle of integrated design, the roller shutter uses locally produced reed curtains, which are low in price, excellent in performance, and adapt to the overall style of the village. The east-west facade of the farmhouse has almost no windows, and uses green shades. A bracket made of thin steel wires is pre-built at a distance of $50 \mathrm{~mm}$ from the outer wall of the farmhouse to facilitate plant climbing (Figure 2).

\subsubsection{Renewable energy utilization design}

Shandong has abundant solar energy resources. Therefore, farmhouses have applied technologies such as solar water heating systems, solar pebble beds, and solar fresh air systems. The green farm house uses a flat-plate solar water heater, and the placement of the heat collecting plate and the size of the reserved hole are considered in advance when designing the roof, which is convenient for assembly installation. The color texture of the heat-collecting panels laid on the sloped roof is similar to the roof tiles. The water storage tank is placed in the bathroom, which does not affect the appearance of the farm house. In northern areas, beds are often replaced by maggots. Solar pebbles maggots are used in the elderly rooms of green farm houses. Hot water coils are installed in the maggots to provide hot water for heating by solar water heating systems. The heat in hot water is stored during the day, and the auxiliary heating carcass is gradually released at night. In addition, the bottom of the sun puppet is overhead, which can reduce the heat loss and form a storage space. An aluminum solar fresh air duct is designed on the top of the sunspace of the farmhouse. When the weather is clear in winter, the fresh air entering the duct is heated by solar energy and sent to various rooms in the room via a low-power fan for supplementary heating.

\subsection{Analysis of Building Energy Consumption and Indoor Temperature Based on Computer Simulation}

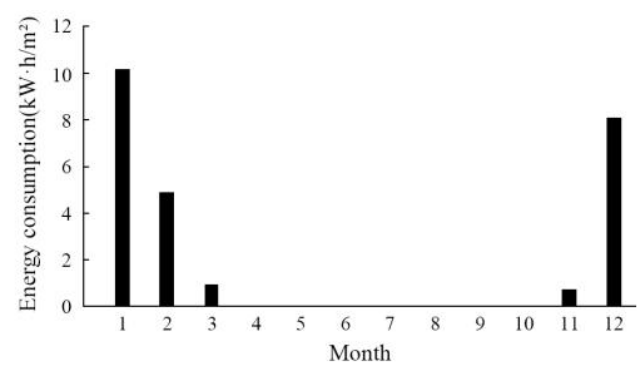

Figure 7 Energy consumption of farm house

In order to verify whether the green farmhouse has achieved the goal of energy saving and consumption reduction, computer software DesignBuilder is used to simulate the heating energy consumption of the design practice throughout the year. First establish the energy consumption model, and then set the parameters such as the heat transfer coefficient of the envelope structure, the window-to-wall ratio, etc., and the winter indoor temperature takes $14^{\circ} \mathrm{C}[7]$. According to the simulation, the accumulated heating energy consumption of the green farmhouse is about $5613.86 \mathrm{~kW} \cdot \mathrm{h}$, and the building area of the farmhouse is $204 \mathrm{~m}^{2}$. Therefore, the cumulative heating energy consumption per unit area is about $27.52 \mathrm{~kW} \cdot \mathrm{h} / \mathrm{m}^{2}$ (Figure 7). At present, buildings with a cumulative heating energy consumption per unit area of less than $70 \mathrm{~kW} \cdot \mathrm{h} / \mathrm{m}^{2}$ throughout the year are generally defined as low-energy buildings[8], so green farmhouses can meet the standards for low-energy buildings.

In order to verify whether the indoor temperature of the green farmhouse is comfortable and reasonable in winter, the temperature of each indoor room for three consecutive days in late December was simulated and analyzed. As shown in Figure 8, when the minimum outdoor temperature reaches $-7^{\circ} \mathrm{C}$, the temperature of 


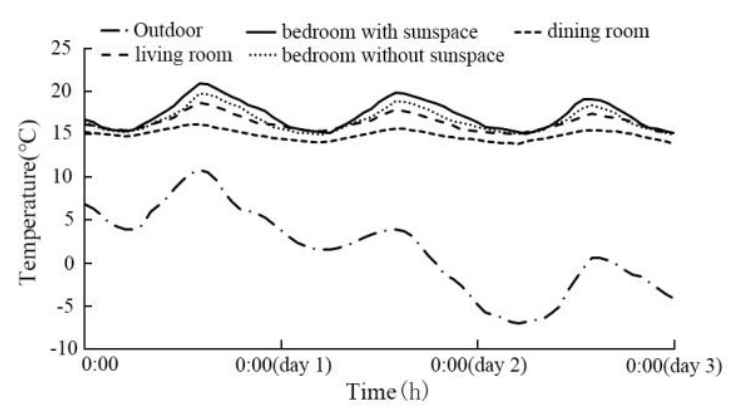

Figure 8 Temperature change of farmhouses in winter

each room can still is maintained at above $14^{\circ} \mathrm{C}$, and the highest can even reach $21^{\circ} \mathrm{C}$. Comparing the south-facing living room, bedroom and north-facing dining room, it can be seen that the room temperature of the south-facing room is generally higher than $3^{\circ} \mathrm{C}$ compared with the north-facing room. Comparing bedrooms with sunspace and bedrooms without sunspace in the south direction, it can be seen that in sunny days, the room with a sunspace was $2-3^{\circ} \mathrm{C}$ higher than the room without a sunspace. It can be seen that even in the cold winter outdoor temperature, the green farm house can still maintain a more comfortable thermal environment. In addition, the flat space layout of the farm house has a significant effect on the room temperature of each room, and the setting of the sun room is a very effective method in increasing the indoor temperature.

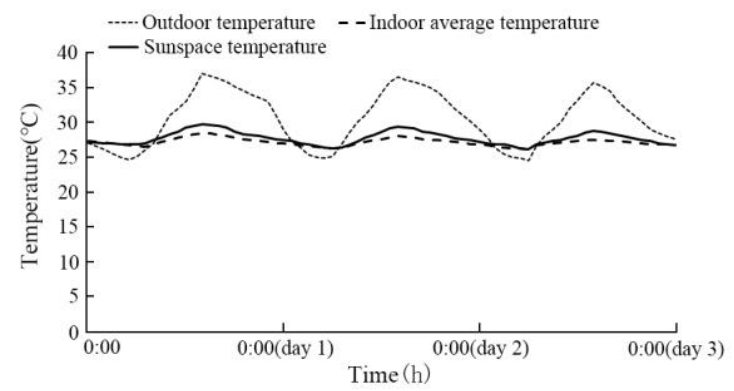

Figure 9 Temperature change of farmhouses in summer

In order to verify whether a design strategy that is good for winter insulation will cause indoor overheating in summer, the indoor temperature of a farmhouse without air conditioning for three consecutive days in mid-August was simulated. In the summer of Shandong, the day is hot and the night is cool, so when the outdoor temperature is higher than the indoor temperature during the day, the most effective way to make the room comfortable is to open the shading facilities and ensure the ventilation between the sun, and the remaining rooms are closed; when the outdoor temperature is lower than the indoor temperature at night, an effective cooling method is to use ventilation to remove excess heat from the room. According to this method, the model parameters and simulate the temperature curve. As shown in Figure 9, when the maximum outdoor temperature reaches $37^{\circ}$, the indoor temperature of the green farmhouse can be controlled at about $28^{\circ} \mathrm{C}$ during the day and $26^{\circ} \mathrm{C}$ at night. The temperature between sunlight and daytime is only slightly higher than the indoor average temperature, and the increase is only about $1{ }^{\circ} \mathrm{C}$. It can be seen that there is no indoor overheating in the green farmhouse in summer, and the ventilation, shading and other design strategies used in the farmhouse have a good effect for preventing heat and cooling.

\section{Conclusion}

Under the premise that rural farmhouses generally have high energy consumption and low comfort, in this paper, the design practice of prefabricated steel structure green farmhouses in Zibo, Shandong was taken as an example to discuss the design methods of green farmhouses in cold areas. Based on environmental characteristics, regional characteristics and technical conditions, this design practice put forward corresponding design strategies from the aspects of building shape, functional space layout and appropriate green technology. The computer simulation results show that the energy consumption of the green farm house is low and it has a comfortable indoor thermal environment, which verifies the effectiveness of the farm house design strategy. The farm house practice finally achieved the design goal of reasonable function, green and sustainable, reached the optimization of energy consumption and economy in the whole life cycle of the building, and played a certain demonstration role for the construction of rural farm houses in Shandong.

\section{References}

1. L. Jiang, X.P. Chen, B. Xue, Sustainability 11(2019)

2. Y.Y. Zhu, X.N. Fan, G.C. Sang, et al. J Phys Conf Ser 1176(2019)

3. B. Cao, Y.X. Zhu, M. Li, et al. Energy and Buildings 78, 17-24(2014)

4. N. N. Shao, J.L. Zhang, L. D. Ma, Journal of Building Engineering 12,229-238(2017)

5. F. Qi, Cui. F, Lv. W, et al. Build. Simul. 12,597-604(2019)

6. J.F. Chen, T.T. Du, Architectural Journal 14,22-28(2016)

7. MOHURD, Design Standard for Energy Efficiency of Rural Residential Building, China Building Industry Press (2013)

8. Y. Shao, X.H. Zhou, Y.P. Meng, et al. Architectural Journal 5,77-80(2016) 